\title{
Developing Algorithm for Random Distribution of Nanomaterials
}

\author{
Umut Çalışkan ${ }^{1 *}$ \\ 1* Erciyes University, Faculty of Engineering, Departmant of Mechanical Engineering, Kayseri, Turkey, (ORCID: 0000-0002-8043-2799), ucaliskan@erciyes.edu.tr
}

(2nd International Conference on Access to Recent Advances in Engineering and Digitalization (ARACONF)-10-12 March 2021)

(DOI: $10.31590 /$ ejosat.916108)

ATIF/REFERENCE: Çalışkan, U. (2021). Developing Algorithm for Random Distribution of Nanomaterials. European Journal of Science and Technology, (24), 508-514.

\begin{abstract}
In this study, a new algorithm was developed for the random distribution of the nanomaterials in the polymer matrix to model realistic behavior of polymer nanocomposites. The study focused on the development of this algorithm rather than the modeling of nanocomposites as a finite element method. The multi-scale method with a representative volume element (RVE) is generally used for numerical modeling of nanomaterials and polymer nanocomposites. The researchers investigate the effect of the reinforcement material and the reinforcement mechanism has not been fully explained both numerically and experimentally. The success of numerical studies is also very important to specify the effect of reinforcement mechanism in experimental studies. For this reason, an algorithm was developed to model the realistic distribution of nanomaterials in the polymer matrix and adapted to numerical studies. The algorithm provided that materials of desired geometric dimensions were randomly positioned within a control volume and did not intersect with each other and the control volume. The algorithm was developed using the Python programming language and the positions of the nanomaterials were transferred to the ABAQUS finite element program using scripting language. Graphene was used as a nanomaterial and epoxy was used as a polymer matrix. Randomly distributed RVE models gave more successful results than single element RVE models. It shows a good agreement with experimental results.
\end{abstract}

Keywords: Random Distribution, Algorithm, Nanomaterials, Graphene.

\section{Nanomalzemelerin Rastgele Dağılımı İçin Algoritma Geliştirilmesi}

$\ddot{O} \mathbf{z}$

$\mathrm{Bu}$ çalışmada, polimer nanokompozitlerin gerçekçi davranışını modellemek için nanomalzemelerin polimer matriks içerisindeki rastgele dağılımını saplayan yeni bir algoritma geliştirilmiştir. Çalışma nanokompozitlerin sonlu elemanlar yöntemi olarak modellenmesinden ziyade bu algoritmanın geliştirilmesine odaklanmıştır. Nanomalzemelerin ve polimer nanokompozitlerin sayısal modellemesine genellikle temsili hacim elemanına sahip çok ölçekli moelleme yöntemi kullanılmaktadır. Takviye malzemesinin etkisi araştırmacılar tarafından araştırılmakta olup takviye mekanizması hem sayısal hem de deneysel olarak tam olarak açıklanmamıştır. Deneysel çalışmalarda takviye mekanizmasının etkisini anlamak için sayısal çalışmaların başarısı da oldukça önemlidir. Bu nedenle, nanomalzemelerin polimer matrisindeki gerçekçi dağılımını modellemek için bir algoritma geliştirilmiş ve sayısal çalışmalara uyarlanmıştır. Algoritma, istenen geometrik boyutlara sahip malzemelerin bir kontrol hacmi içinde rastgele konumlandırılmasını ve birbirleriyle ve kontrol hacmi ile kesişmemesini sağlamaktadır. Algoritma Python programlama dili kullanılarak geliştirilmiş ve nanomalzemelerin konumları komut dosyası dili kullanılarak ABAQUS sonlu eleman programına aktarılmıştır. Nanomalzeme olarak grafen ve polimer matriks olarak epoxy kullanılmıştır. Rastgele dağıtılan RVE modelleri, tek elemanlı RVE modellerinden daha başarılı sonuçlar vermiştir. Deneysel sonuçlarla iyi bir uyum göstermiştir.

Anahtar Kelimeler: Rastgele dağılım, Algoritma, Nanomalzemeler, Grafen.

\footnotetext{
*Corresponding Author: ucaliskan@erciyes.edu.tr
} 


\section{Introduction}

Polymer materials reinforced with nanoparticles have recently attracted great attention in both scientific and industrial communities due to their superior properties. Graphene nano platelets as an additives material in small volume fractions can be added to improving the mechanical properties of polymers. (Kim et al., 2010;Potts et al., 2011; Geim and Novoselov, 2007; Cho et al., 2006; Tjong, 2006). Researchers have shown an extraordinary interest to graphene as a nano reinforcement due to its extraordinary mechanical properties. Many researches (Georgantzinos et al., 2010; Shokrieh and Rafiee, 2010; Tsai and Tu, 2010; Shokrieh et al., 2012; Shen et al., 2010) have been performed on modeling of graphene sheet to characterize its properties.

Shokrieh et al. (2017) developed a new approach for prediction of the stiffness of polymer nanocomposites with randomly distributed graphene sheets. The finite element and micromechanics methods was used for this approach. They used a finite element method to calculate stiffness of the nanocomposites with nano graphene embedded in a polymer. Structural beam was used to model covalent bond of graphene and continuum solid element was used to model for matrix materials. They used nonlinear spring elements for Van der Walls bonds in the interface region between graphene and polymer. It is impossible to model graphene as real size in the represent volume element. They used a new approach to overcome this issue. Different graphene sheets in the different sizes were used in the represent volume element in the new approach to to predict the stiffness of real size graphene with matrix. The micromechanics approach using finite element method was used to understand the effect of the random distrubition. The results of developed model was in good aggrement with the experimental ones. Manta et al. (2018) focused to validate the numerical results of graphene/polymer nanocomposite with electrical behaviour using experimental data. The multiscale method with a representative volume element (RVE) was used for aligned and randomly distributed nanoparticles. The material modeling was considered at the micro-level with a user-defined distribution of the unit cell. The direct (DC) and alternate current (AC) was compared the electrical response with a statistical sample. They investigated nanocomposite electrical behavior with different volume fraction and loading frequency. Dai and Mishnaevsky Jr. (2014) studied 3D numerical model of graphene reinforced polymer composites with damage and fracture mechanisms. The inverse modeling technique was used to model the graphene/polymer interface. If the aspect ratio, volume content and elastic properties of graphene/polymer interface layer increases, Young modulus of the nanocomposites increases. Randomly oriented graphene exhibit lower Young modulus and strength comparing with the aligned graphene nanocomposites.

Shokrieh et al., (2014) predicted the mechanical behavior of randomly distributed graphene/polymer nanocomposites using molecular dynamics and micromechanics approach. The nano graphene was investigated in terms of the different length and width dimension. The stiffness of aligned one layer graphene embedded in epoxy was predicted using molecular dynamics approach and the stiffness of randomly distribution graphene epoxy was predicted using micromechanical approach. An experimental set-up was performed to evaluate the capability of the numerical model. The result of the numerical model was very similar the experimental ones. Hadden et al., (2015) used the multi-scale method to investigated the mechanical properties of graphene/carbon fiber/epoxy hybrid composites. The effect of the graphene volume fraction, epoxy density, and graphene dispersion on the mechanical performance were studied. They developed the multiscale modeling approach with molecular dynamics and micromechanical method. They validated the results with experimental ones. Graphene volume fraction and distribution has a significant influence on the transverse mechanical properties of the hybrid composite. Its effect on axial properties is insignificant. Hussein and Kim, (2018) studied the stiffness of graphene polymer matrix nanocomposites. The study focused on the effect of the matrix modulus on the strain fields. Perfect bonding with graphene and interface of polymer with no agglomeration was considered. The matrix of the nanocomposites played an active role in stiffening with large strains level. Strain energy was measured the effect of the nonuniform strain fields in nanocomposites. They developed novel synthesis methods to enhance the graphene and its interface quality. Pontefisso and Mishnaevsky Jr. (2016) investigated the effect of the morphology, shape and distribution of nanoscale carbon reinforcement in polymers. They developed a new software and approach for the automatic generation of finite element unit cell models of nanocomposites. They studied the effect of curved, zigzagged, snakelike shapes of real carbon nanotubes and graphene on the damage evolution in the computational experiments based on the developed code. The potential of hybrid (carbon nanotubes and graphene) nanocomposites was studied with view on its effect of damage resistance.

The objective of this study is to develop an algoritm for random distrubition of nanomaterials in the polymer matrix as grafen/polymer nanocomposites and understand the influence of the random distrubition on the mechanical behavior of graphene nanocomposites. The mechanical behavior of nanocomposite was determined using molecular-micro mechanics approach with mult-scale finite element method. The multi-scale model and randomly distributed polymer nanocomposited results were valeted using experimental results from litreture. The algorithm of random distribution was developed using analytical geometry, engineering mathematics with python scripting language.

\section{Material and Method}

\subsection{Problem Statement}

In computational nanomechanics, the energy of a system including several hundred to billions atoms is evaluated using interatomic potentials. The total potential energy function of an n-body nanostructure, always understood to refer to the configurational potential energy that can be expressed in terms of coordinates of its constituent atoms. The proposed model aims to predict the mechanical behaviour of graphene/polymer nanocomposites more accurately in accordance with the actual behavior. The finite element and micromechanics methods were used to model nanocomposites. The nanocomposites with randomly distributed graphene with real geometric shape was modelled using the representative volume element (RVE) in the polymer matrix. In predicting these behaviors, the use of a graphene nanoparticle aligned within the polymer matrix in the RVE model leads us to wrong conclusions in terms of actual behavior. Therefore, it was planned to get closer results to the 
real behavior in the simulations by considering the real graphene distribution in the polymer.

\subsection{Modeling Method}

\subsubsection{Molecular Structural Mechanics and Graphene}

In this section, the modeling techniques of graphene geometry, molecular structural mechanics and RVE are expianed. Figure 1 shows the one layer gpahene sheet with atoms and $\mathrm{C}-\mathrm{C}$ bonds.

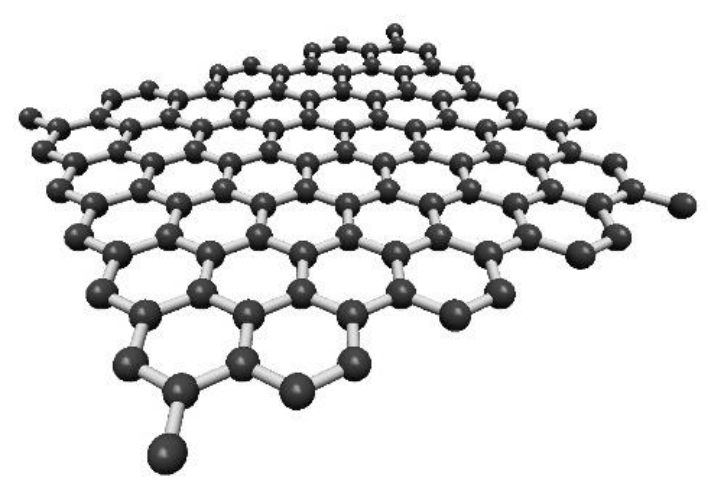

Figure 1. Graphene sheet

Shokrieh et al. (2017) simulated the mechanical response of graphene/polymer nanocomposites and used modeling technique in the atomistic scale. They used structural beam elements to model the covalent bonds (Carbon-Carbon bonds, CC) between the carbon atoms (Figure 2). The variation of potential energies between atoms was related to the stress energies of the structural beams. The relationships obtained by their methods are as follows:

$\frac{E A}{L}=k_{r}, \quad \frac{E I}{L}=k_{\theta}, \quad \frac{G J}{L}=k_{\tau}$,

where $k_{r}, k_{\theta}$ and $k_{\tau}$ represent the bond stretching force constant, bond bending force constant and bond torsional resistance. Moreover, E, G, A, I, J and L are the Young's modulus, shear modulus, cross section area, second moment of area and polar moment of area of the equivalent beam, respectively.

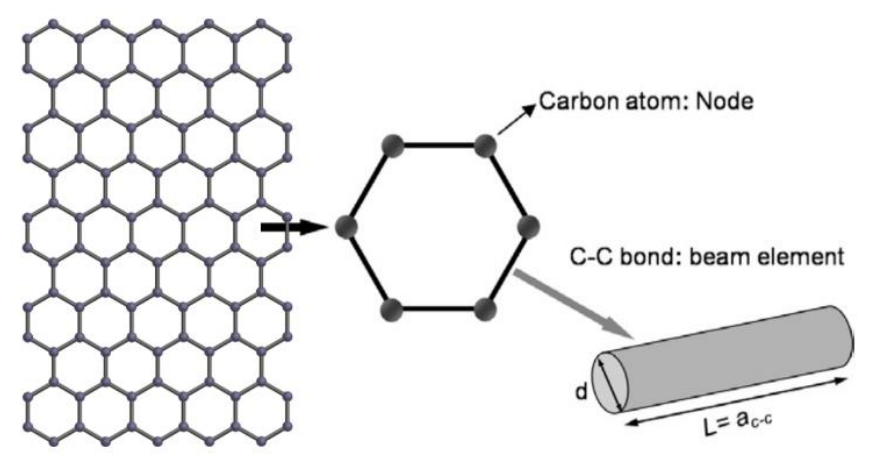

Figure 2. Model of graphene sheet as a space-frame structure.

A circular cross section was considered for the beam elements. According to Amber force field which is related molecular mechanics parameters with E, G and diameter (d) of the beam elements can be applied in structural mechanics modelling (Shokrieh et al., 2017):

$$
d=4 \sqrt{\frac{k_{\theta}}{k_{r}}}, \quad E=\frac{k_{r}^{2} L}{4 \pi k_{\theta}}, \quad G=\frac{k_{r}^{2} k_{\tau} L}{8 \pi k_{\theta}^{2}}
$$

Table 1. AMBER force field parameters.

\begin{tabular}{lr}
\hline Parameter & Value \\
\hline$k_{r},\left(938 \mathrm{kcal} \mathrm{mol}^{-1} \mathrm{~A}^{-2}\right)$ & $6.52 \times 10^{-7} \mathrm{~N} \mathrm{~nm}^{-1}$ \\
$k_{\theta},\left(126 \mathrm{kcal} \mathrm{mol}^{-1} \mathrm{rad}^{-2}\right)$ & $8.76 \times 10^{-10} \mathrm{~N} \mathrm{~nm}^{-1} \mathrm{rad}^{-2}$ \\
$k_{\tau},\left(40 \mathrm{kcal} \mathrm{mol}^{-1} \mathrm{rad}^{-2}\right)$ & $2.78 \times 10^{-10} \mathrm{~N} \mathrm{~nm}^{-1} \mathrm{rad}^{-2}$ \\
\hline
\end{tabular}

The finite element method was applied to this formulation to solve the system of matrices. Each node has six degrees of freedom (DOF), three translational $(\mathrm{x}, \mathrm{y}, \mathrm{z})$ and three rotational degrees of freedom (DoF).

\subsubsection{Represented Volume Element, RVE}

In this study, molecular structural modelling considers the Euler-Bernoulli beam element. This beam element are using the elastic parameters such as E and $\mathrm{G}$ and also on diameter which are obtained from molecular structural modelling method. A space-frame structure model was used to model the beam element and geometrical modeling through coordinates of carbon atoms in its molecular structure. The coordinates of atoms were taken from a nanomaterial-modeling program.
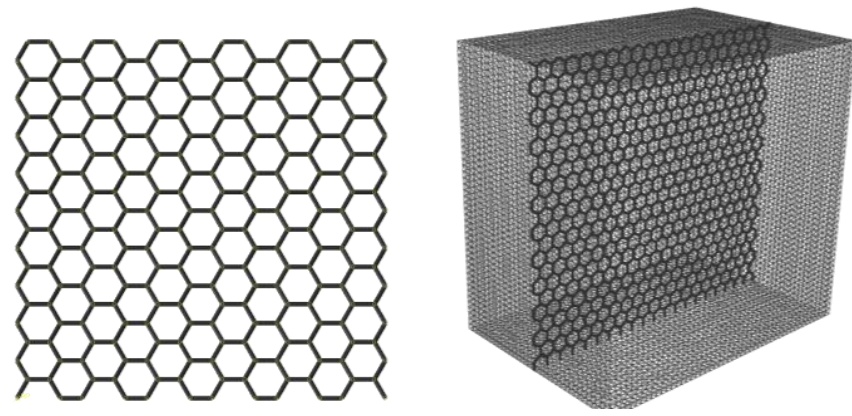

Figure 3. RVE model

The main purpose of multi-scale modelling of nanocomposites is to analyse of a representative of the material system (Figure 3). In this study, different types of RVEs were used which include one layer graphene and randomly distributed graphene in the same weigth fraction ratios.

\subsection{Random Distribution Algorithm}

Random distribution algorithm was developed to simulate realistic behaviour of graphene nanocomposites. This algorithm was generated using Python programing language. Figure 4 shows the flow chart of random distribution algorithm. The random distribution algorithm of nanoparticles in a polymer matrix without intersection each other was created with the following steps: 


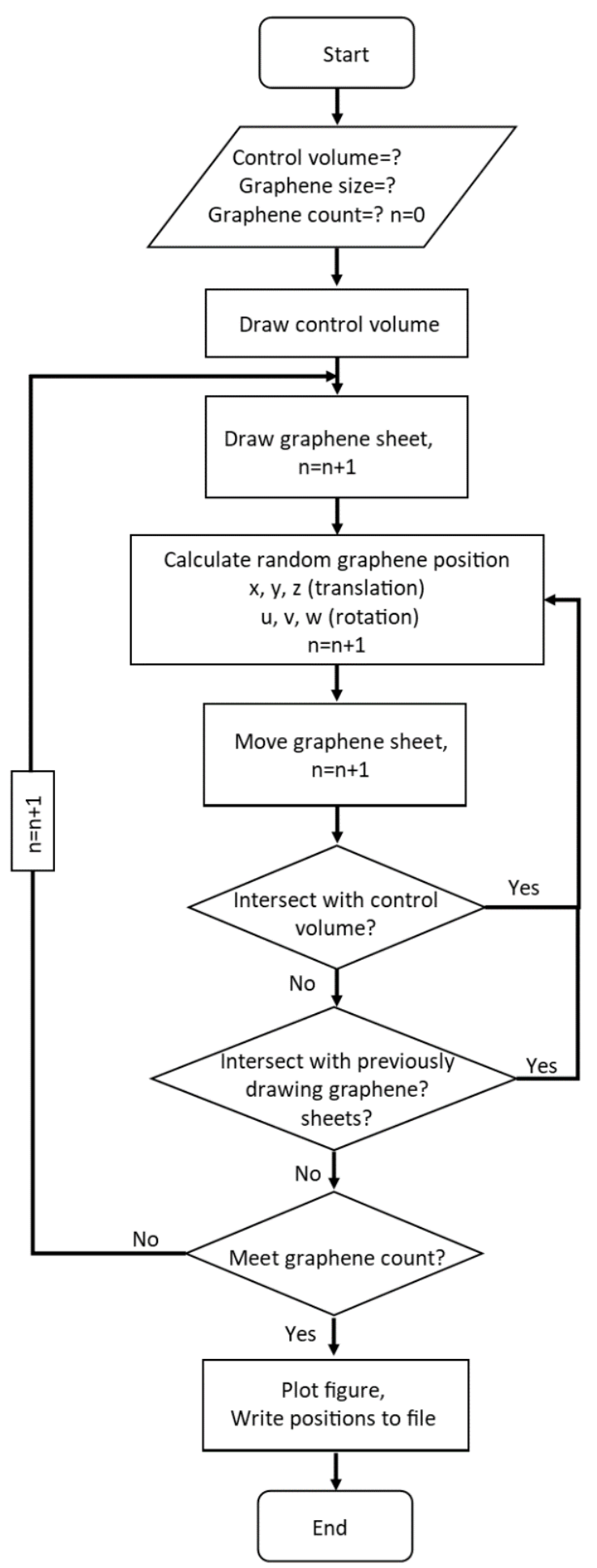

Figure 4. Flow chart of random distribution algorithm

- Input step: Input informations are needed for algorithm logic to work. The algorithm requests from the user for the dimensions of the initial control volume as input. Then it requests for the graphene dimensions as 3D. Finally, the graphene count that is calculated according to the determined volume fraction is needed.

- Drawing step: According to the control volume dimensions received as input from the user, a center in 3 -dimensional space is determined. Control volume in the study means polymeric representative volume element. According to this determined center, the control volume is drawn as a rectangular prism. Then, the 3D shape as graphene in this study is drawn in the center according to the particle sizes taken from the user.

- Generating random coordinate step: In this stage, random coordinates need for the positioning of the drawn geometries within the control volume. Three translation coordinates along the $\mathrm{x}, \mathrm{y}$ and $\mathrm{z}$ axes and three rotation angles around the $\mathrm{x}, \mathrm{y}$ and $\mathrm{z}$ axes whose boundaries are within the control volume are randomly generated.

- Moving step: Graphene particles in the center of the control volume are positioned according to randomly generated coordinates considering reference point in the center of the graphene particles.

- Checking intersection step: The steps of the developed algorithm up to this step include classical methods. After the graphene nanoparticle is positioned randomly within the control volume, it is necessary to check whether any of graphene cross-sections intersect with the control volume. And then, the same calculation need to be checked again if a graphene was drawn and positioned before it. The intersection control of the graphene sections by using the algorithm of passing a line through another surface in space was performed. At this stage, the coding logic controls the intersection of a line of the geometric shape and a surface. Figure 5 shows this algorithm logic. Here, the triangle shape represents a surface divided in two triangle of the rectangular prism.

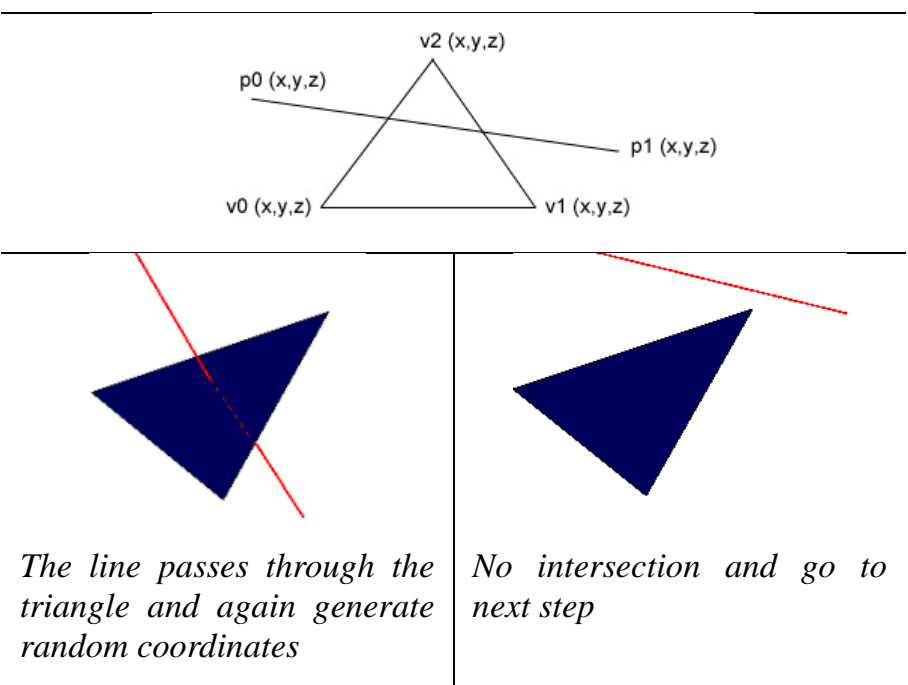

Figure 5. Checking intersection of a surface with a line.

If there is an intersection during the checks, the random coordinates are regenerated. For the graphene positioned according to the randomly generated coordinates, the case of intersections in the early stages is less. As the generated graphene increases, available coordinate will be determined in higher trials. However, these trials take a very short time in terms of computer language. Because the control processes will be repeated for all previously generated graphenes and control volume. As the graphene count taken from input stage is reached, the generation process stops. 
- Output step: The coordinates according to the written algorithm are imported into a text file. In this way, the output file is adapted to the numerical model and the graphene particles are randomly distributed. Figure 6 shows an example for running and plotting code.
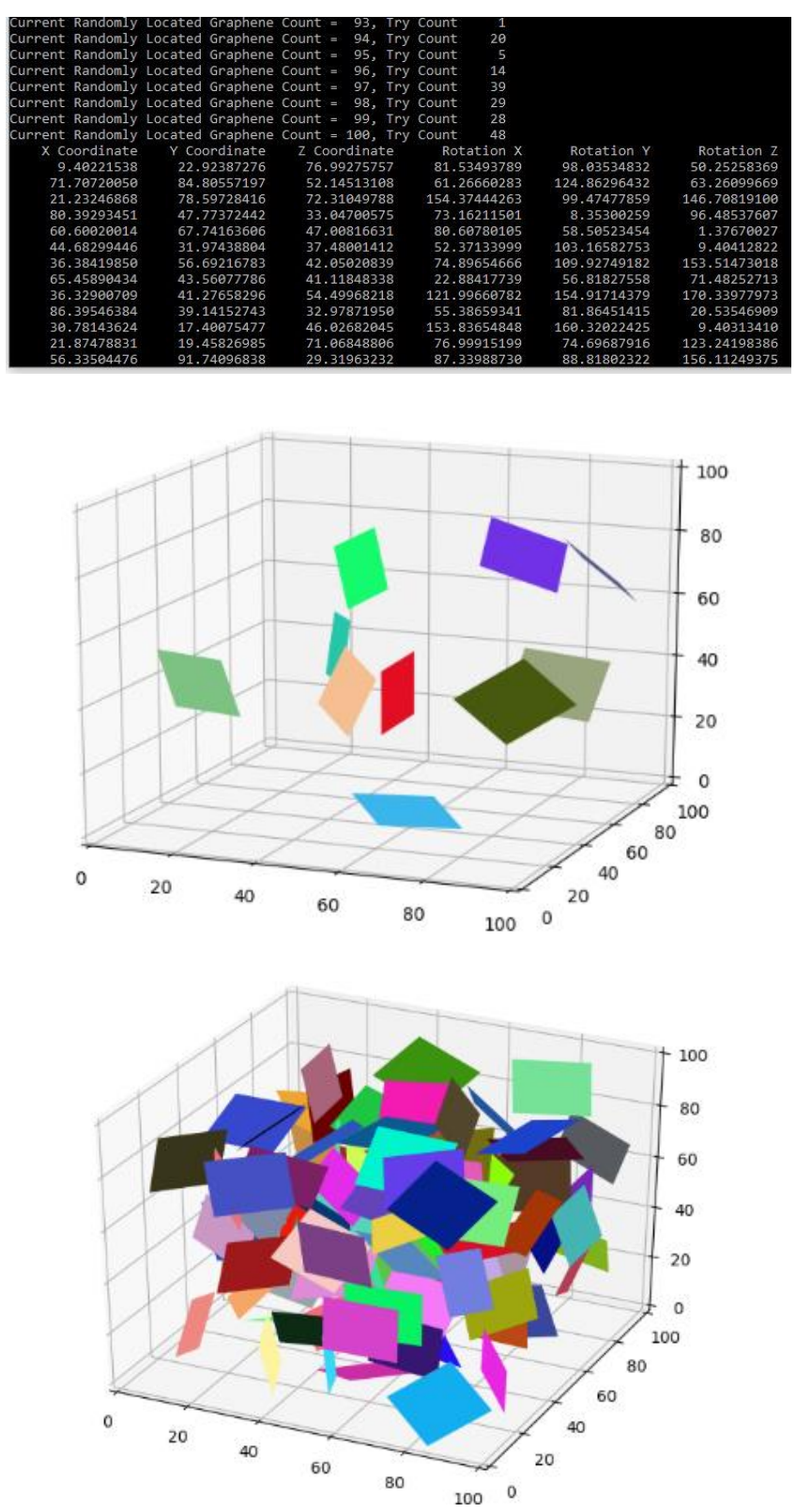

Figure 6. Running and plotting code

\section{Results and Discussion}

In this study, the polymer region was modelled as a continuum phase with tetrahedron mesh algorithm. Tensile behavior was investigated to understand the effect of random distribution of graphene nanomaterials. The experimental results were obtained by taking a current study from the literature. In this way, numerical results can be compared with the experimental ones. In the numerical analysis, tensile force was applied from the top surface of the RVE and bottom surface of the RVE was fixed. Figure 7 shows the RVE models as single and randomly distributed graphene/epoxy nanocomposites. The outputs of the developing algorithm in this study are applied to the RVE model in Figure 7 b. The graphene nanoparticles are randomly distributed within the polymer epoxy without any intersections.

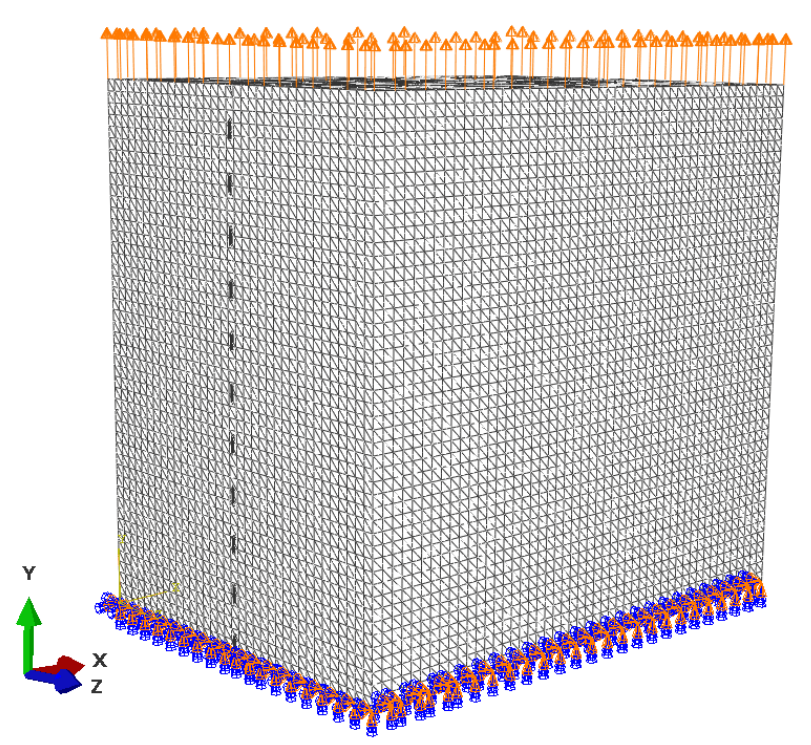

a) Single graphene/epoxy nanocomposite

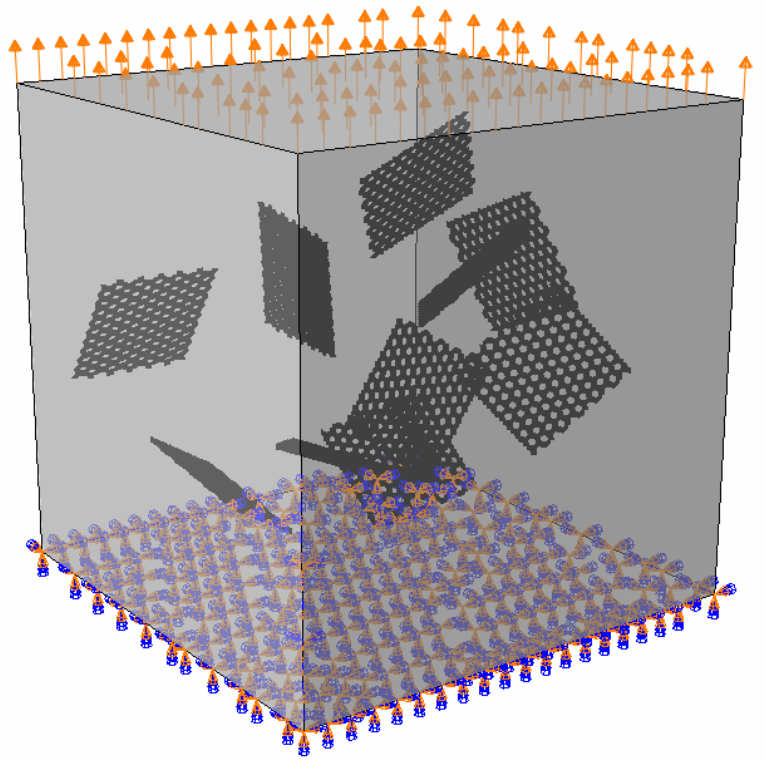

b) Randomly distributed graphene/epoxy nanocomposite

Figure 7. RVE model of single and randomly distributed graphene/epoxy nanocomposites

Since the study from the litreture (Heidarhaei et al., 2020) was considered, neat, 0.1 and 0.2 wt $\%$ graphene/epoxy nanocomposites were modelled using RVE technique. Experimental results were compared with two different numerical models as single and randomly distributed graphene nanocomposites. Figure 8 shows the stress distribution of the randomly distributed graphene nanocomposites. It is clear that from this Figure, loads form the graphene nanoparticles to polymer region or exact opposite were transferred successfully. 


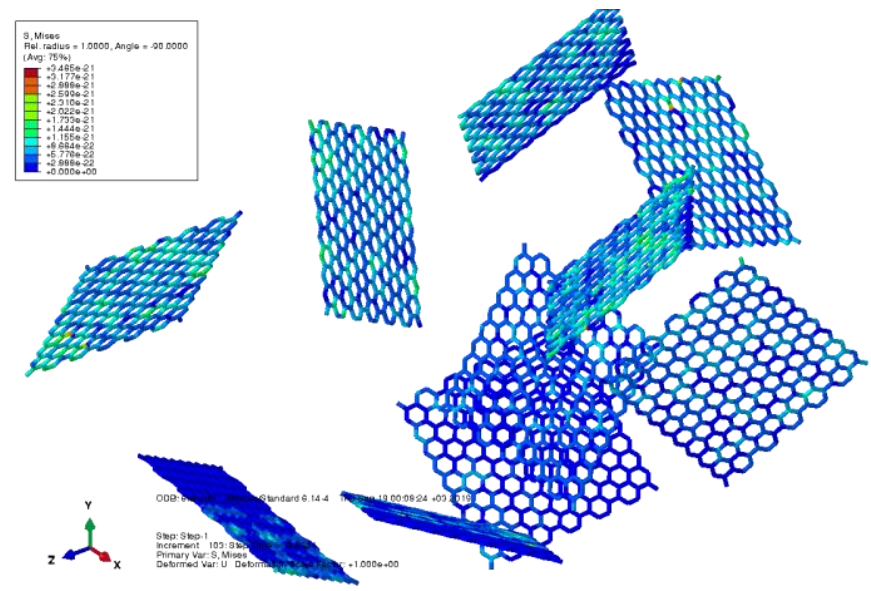

Figure 8. Stress distribution of randomly distributed graphene/epoxy nanocomposites

Figure 9 shows the experimental and numerical stress-strain diagrams of single and randomly distributed graphene nanocomposites. The effect of the graphene reinforcement to neat epoxy is show in Figure 9 a. There are many studies about this subject in the literature and it seems results are generally no consistent. Because there are many problems in the experimental study, in this case it leads to changes in the results. This problem was overcome by selecting an up-to-date study using advanced experimental methods. According to the results of this study, as the graphene reinforcement increases, tensile strength incrases. Figure $9 \mathrm{~b}$ shows the experimental and numerical stress-strain behavior under tension load of the $0.2 \mathrm{wt} \%$ graphene/epoxy nanocomposites. Numerical study was performed using two different model as single and randomly distributed graphene nanocomposites. Single graphene embedded polymer in weigth fraction of $0.1 \%$ behaves more rigit and exhibit higher tensile stress as $90 \mathrm{MPa}$. As the curve trend of numerical results is considered, it is seen that lineer behavior occurs. Because the analysis is completely elastic and plastic behavior occurred in the experimental tension test of polymer. However, randomly distributed graphene nanocomposite exhibit more compatible result with experimental one. Rigitidy decreases using randomly distributed graphene in polymer and the maximum tensile stress is $60 \mathrm{MPa}$ of the nanocomposites. Especially in the elastic region there is quite high similarity with experimental behavior.

Figure $9 \mathrm{c}$ shows the tensile behavior of $0.25 \mathrm{wt} \%$ graphene/polymer nanocomposites. As the maximum tensile stress of single graphene nanocomposites is about $130 \mathrm{MPa}$, randomly distributed graphene nanocomposite gives $80 \mathrm{MPa}$. In the elastic region there is similar trend.

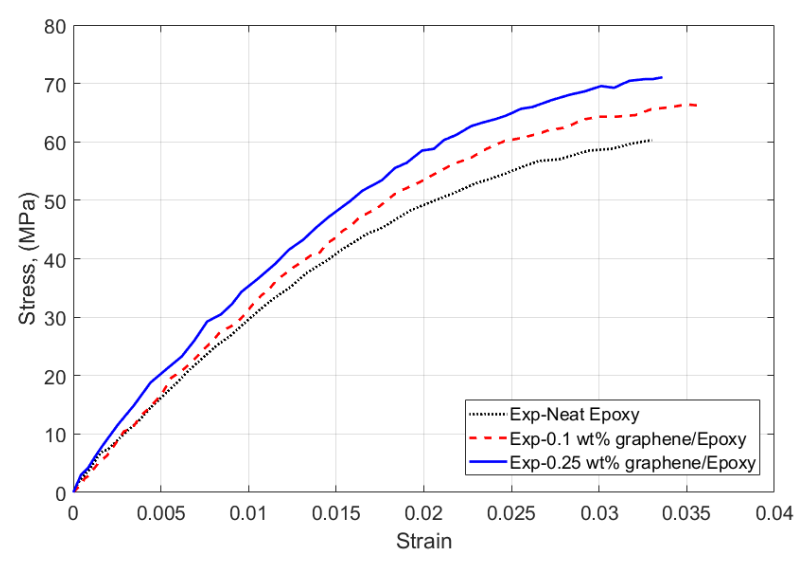

a) Experimental neat and graphene/epoxy nanocomposite (Heidarhaei et al., 2020)

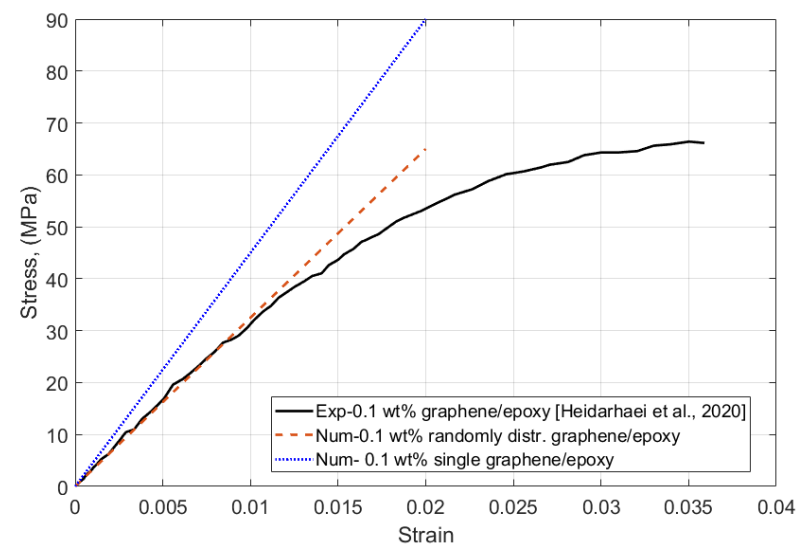

b) Experimental and numerical $0.1 \mathrm{wt} \%$ grapehene/epoxy nanocomposite

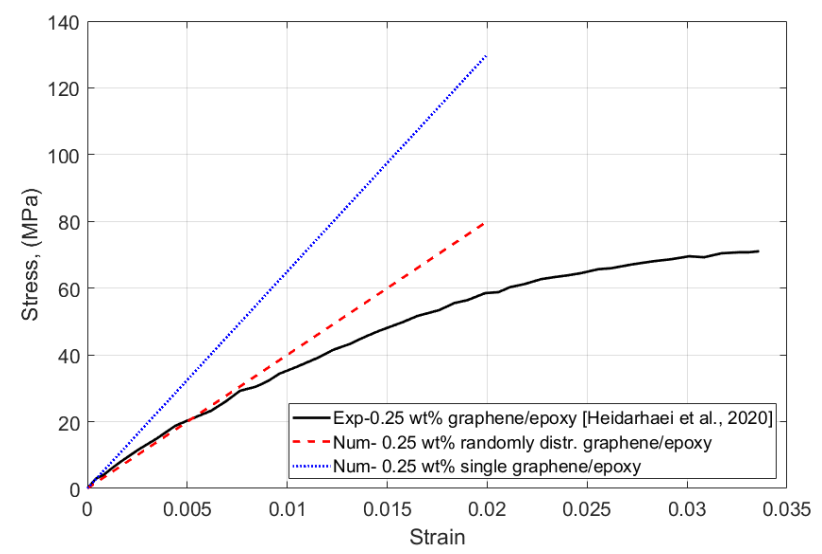

c) Experimental and numerical 0.25 wt $\%$ grapehene/epoxy nanocomposite

Figure 9. Experimental and numerical stress-strain diagrams for neat, 0.1 and $0.25 \mathrm{wt} \%$ graphene/epoxy nanocomposites 


\section{Conclusions and Recommendations}

In the present study, a new algorithm related randomly distributed nanomaterials was developed using the finite element and micromechanics methods. This approach is able to predict the tensile behavior of graphene/epoxy nanocomposites with randomly distributed graphene in the polymer. Using the finite element simulation, the polymer matrix was assumed as a continuum phase and using the atomistic modeling approach, each carbon-carbon bond of the graphene sheet was modeled as a structural beam. Random distribution algorithm was developed to simulate realistic behaviour of graphene nanocomposites using Python programing language. To understand the random distribution effect in nanomaterials, it is compared with the RVE model consisting of a single graphene. Two different weigth fractions of 0.1 and $0.25 \%$ for the graphene reinforcement were used in this study. The RVE model of single graphene behaves more rigid than randomly distributed RVE. All results related with the randomly distributed graphene nanocomposites seem to be in agreement with the experimental results. Developing algoritm can apply for different studies like carbon nanotube nanocomposites or different material type.

\section{References}

Kim, H., Abdala, A. A. and Macosko, C. W. (2010). Graphene/polymer nanocomposites. Macromolecules 43, 6515-6530.

Potts, J. R., Dreyer, D. R., Bielawski, C. W. and Ruoff, R. S. (2011). Graphene-based polymer nanocomposites. Polymer $52,5-25$.

Geim, A. K. and Novoselov, K. S. (2007). The rise of graphene. Nat. Mater 6, 183-191.

Cho, J., Joshi, M. S. and Sun, C. T. (2006). Effect of inclusion size on mechanical properties of polymeric composites with micro and nano particles. Compos. Sci. Technol. 66, 19411952.

Tjong, S. C. (2006). Structural and mechanical properties of polymer nanocomposites. Mater. Sci. Eng. R 53, 73-197.

Georgantzinos, S. K., Giannopoulos, G. I. and Anifantis, N. K. (2010). Numerical investigation of elastic mechanical properties of graphene structures. Mater Des 31, 4646-54.

Shokrieh, M. M. and Rafiee, R. (2010) Prediction of Young's modulus of graphene sheets and carbon nanotubes using nanoscale continuum mechanics approach. Mater Des 31, $790-5$.

Tsai, J. L. and Tu, J. F. (2010). Characterizing mechanical properties of graphite using molecular dynamics simulation. Mater Des 31:194-9.

Shokrieh, M. M., Shokrieh, Z. and Hashemianzadeh, S. M. (2012). Effective parameters in modeling of graphene sheet Young's modulus. Modares Mech Eng 12, 147-55.

Shen, L., Shen, H. S. and Zhang, C. L. (2010). Temperaturedependent elastic properties of single layer graphene sheets. Mater Des 31, 4445-9.

Shokrieh, Z., Seifi, M. and Shokrieh, M. M. (2017). Simulation of stiffness of randomly-distributed-graphene/epoxy nanocomposites using a combined finite elementmicromechanics method. Mechanics of Materials 115, 1621.

Manta, A., Gresil, M., and Soutis, C. (2018). Simulated electrical response of randomly distributed and aligned graphene/polymer nanocomposites. Composite Structures 192, 452-459.

Dai, G. and Mishnaevsky, Jr., L. (2014). Graphene reinforced nanocomposites: 3D simulation of damage and fracture. Computational Materials Science 95, 684-692.

Shokrieh, M. M., Shokrieh, Z. and Hashemianzadeh, S. M. (2014). A novel combined molecular dynamicsmicromechanics method for modeling of stiffness of graphene/epoxy nanocomposites with randomly distributed graphene. Materials and Design 64, 96-101.

Hadden, C. M., D. R., Klimek-McDonald, Pineda, E. J., King, J. A., Reichanadter, A. M., Miskioglu, I., Gowtham, S. and Odegard, G.M. (2015). Mechanical properties of graphene nanoplatelet/carbon fiber/epoxy hybrid composites: Multiscale modeling and experiments, Carbon 95, 100-112.

Heidarhaei, M., Shariati, M. and Eipakchi, H. (2020). Experimental and analytical investigations of the tensilebehavior of graphene-reinforced polymer nanocomposites, Mechanics of Advanced Materials and Structures 27, 2090-2099.

Hussein, A., kim, B. (2018). Graphene/polymer nanocomposites: The active role of the matrix in stiffening mechanics, Composite Structures, 202, 170-181.

Pontefisso, A., Mishnaevsky Jr., L. (2016). Nanomorphology of graphene and CNT reinforced polymer and its effect on damage: Micromechanical numerical study, Composites Part B, 96, 338-349. 